\title{
COGNITIVE FUNCTION IN GIRLS WITH ADHD
}

Neuropsychological performance of 43 girls, aged 6 to 17 years, with ADHD and 36 controls without ADHD was assessed at the Massachusetts General Hospital, Boston. Girls with ADHD were significantly more impaired on tests of attention, intellectual performance, and achievement, and had higher rates of learning disability than controls. In contrast, impairments in performance on measures of executive function, learning, and memory were not significant. (Seidman LJ, Biederman J, Faraone SV, et al. A pilot study of neuropsychological function in girls with ADHD. I Am Acad Child Adolesc Psychiatry March 1997;36:366-373). (Reprints: Dr Biederman, Pediatric Psychopharmacology Unit (ACC 725), Massachusetts General Hospital, Fruit Street, Boston, MA 02114).

COMMENT. Neuropsychological deficits involving executive function are less remarkable in girls than in boys with ADHD, but impairments of intellectual function, attention, and arithmetic and reading are common to both sexes. Psychiatric comorbidity is not a factor in the occurrence of cognitive dysfunction in children with ADHD.

\section{DIABETES, HYPOGLYCEMIA, AND COGNITIVE DYSFUNCTION}

The effects of diabetes and of episodes of severe hypoglycemia on cognitive function in 28 diabetic children were assessed at the Trondheim University Hospital, Norway. Early-onset diabetes, before age 5 years, complicated by episodes of severe hypoglycemia, was associated with mild impairments of psychomotor efficiency and attention. Diabetes per se and occasional episodes of severe hypoglycemia had no effect on cognitive function in children with late-onset diabetes, after age 5 years. (Bjorgaas M, Gimse R, Vik T, Sand T. Cognitive function in type 1 diabetic children with and without episodes of severe hypoglycemia. Acta Paediatr Feb 1997;86:148-153). (Respond: Dr M Bjorgaas, Trondheim University Hospital, N-7006 Trondheim, Norway).

COMMENT. Early onset childhood diabetes complicated by episodes of severe hypoglycemia may be associated with mild cognitive dysfunction. A possible link between severe hypoglycemia and cognitive impairment in young adult diabetics was considered doubtful in a University of Edinburgh report. (see Ped Neur Briefs Nov 1996;10:88). The diabetes per se may be a more important factor in causation of diabetes-related cognitive impairment in children.

Thyroid and neurological development. Thyroxine supplements $(8 \mathrm{mcg} / \mathrm{kg})$ in 200 infants born at less than 30 weeks' gestation failed to improve developmental outcome at 24 months, in a study at the University of Amsterdam and Emma Children's Hospital, Amsterdam, the Netherlands. (van Wassenaer AG, Kok JH, de Vijlder JJM et al. N Engl I Med Jan 2 1997;336:21-26).

\section{TRICYCLIC ANTIDEPRESSANTS AND SUDDEN DEATH}

Two cases of sudden death in children treated with tricyclic antidepressants for psychiatric disorders are reported from the Children's Hospital, Seattle, WA. A boy, aged 9 years, died after 5 weeks treatment with desipramine, $100 \mathrm{mg}$ hs, for depression; cardiac arrest was preceded by complaint of stomach pains followed by convulsive movements. A boy, aged 7 years, died after treatment with imipramine, $150 \mathrm{mg}$ hs and thioridazine, $25 \mathrm{mg}$ 
prn, for depression, oppositional defiance, and learning disorder; he collapsed and died in cardiac arrest after running several blocks home from school. Autopsies in both patients revealed no cardiovascular or brain abnormalities. Tricyclic antidepressant blood levels were $2000 \mathrm{ng} / \mathrm{ml}$ (case 1), and 10000 $\mathrm{ng} / \mathrm{ml}$ (case 2). (Varley CK, McClellan J. Case study: Two additional sudden deaths with tricyclic antidepressants. I Am Acad Child Adolesc Psychiatry March 1997;36:390-394). (Reprints: Dr Varley, Department of Child Psychiatry, CL-08, Children's Hospital and Medical Center, PO Box 5371, Seattle, WA 98105).

COMMENT. The authors cite 5 reported cases since 1990 of sudden death in children treated with desipramine. One additional case involving desipramine and one with imipramine are reported. The actual risk of cardiac arrest associated with tricyclic antidepressants in children is unknown but is probably underreported. Informed consent and cardiac monitoring are advised, and the authors question the use of desipramine as a first-line antidepressant in children.

\section{ANALYSIS OF PEMOLINE-ASSOCIATED HEPATIC FAILURE}

A search of online computerized medical data-bases (Medline, Peruse) at McGill University, Montreal, Canada, revealed four reported cases of fatal fulminant hepatic failure (FHF) associated with pemoline (Cylert) use as a treatment for attention deficit hyperactivity disorder. Transient increases in hepatic enzymes, with or without symptoms of hepatitis, have been reported in several articles. Of the four reported cases of FHF, one was a deliberate pemoline overdose, one had preexisting cirrhosis, a third developed FHF after addition of methylphenidate (MPH), and one had taken pemoline alternating with MPH for 5 years and pemoline alone for one year. Of these cases, only one appeared justified. The risk of hepatic failure with pemoline may have been overemphasized, but precautions with its use are advised. (Shevell M, Schreiber R. Pemoline-associated hepatic failure: a critical analysis of the literature. Pediatr Neurol Jan 1997;16:14-16). (Respond: Dr Shevell, A-514, Montreal Children's Hospital, 2300 Tupper, Montreal, Quebec, Canada H3H 1P3).

COMMENT. Since the presentation of this article for publication, Abbott Laboratories has notified practitioners of the concern regarding further cases of pemoline associated hepatic failure, and the FDA has advised that pemoline should not be prescribed as a first line treatment for ADHD. Preexisting liver disease is a contraindication, and polytherapy with methylphenidate should be avoided. Baseline and monthly routine liver function monitoring are probably advisable, although the value of this screening in prediction and prevention of hepatic failure is unproven. Significant increases in liver enzymes or symptoms of hepatic dysfunction, such as nausea, anorexia, vomiting, and jaundice, are indications for immediate withdrawal of pemoline treatment. The authors propose a central registry for cases of pemoline-associated hepatic failure.

Amantadine hydrochloride, a dopamine agonist, adjunct treatment for ADHD, is reported of value in 30 children who failed to respond to stimulant therapy. The doses employed were $75 \mathrm{mg}$ bid in liquid form $(50 \mathrm{mg} / 5 \mathrm{ml})$, for children 8 years of age and younger, and $100 \mathrm{mg}$ bid as $100 \mathrm{mg}$ capsules, for children 9 years of age and older. Advantages of amantadine over tricyclic antidepressants and antihypertensive agents used as adjunct therapies for ADHD include freedom from cardiovascular effects and effects on appetite, and lack of daytime sedation. Vivid dreams were the only 